\title{
The Neutral Gas and Ion Mass Spectrometer on the Mars Atmosphere and Volatile Evolution Mission
}

\author{
Paul R. Mahaffy • Mehdi Benna • Todd King • Daniel N. Harpold · Robert Arvey • \\ Michael Barciniak • Mirl Bendt • Daniel Carrigan - Therese Errigo • Vincent Holmes • \\ Christopher S. Johnson • James Kellogg • Patrick Kimvilakani • Matthew Lefavor • \\ Jerome Hengemihle · Ferzan Jaeger • Eric Lyness • John Maurer • Anthony Melak • \\ Felix Noreiga - Marvin Noriega - Kiran Patel • Benito Prats · Eric Raaen • \\ Florence Tan · Edwin Weidner • Cynthia Gundersen - Steven Battel · Bruce P. Block • \\ Ken Arnett · Ryan Miller · Curt Cooper · Charles Edmonson · J. Thomas Nolan
}

Received: 14 September 2013 / Accepted: 20 August 2014 / Published online: 11 September 2014

(C) The Author(s) 2014. This article is published with open access at Springerlink.com

\begin{abstract}
The Neutral Gas and Ion Mass Spectrometer (NGIMS) of the Mars Atmosphere and Volatile Evolution Mission (MAVEN) is designed to measure the composition, structure, and variability of the upper atmosphere of Mars. The NGIMS complements two other instrument packages on the MAVEN spacecraft designed to characterize the neutral upper atmosphere and ionosphere of Mars and the solar wind input to this region of the atmosphere. The combined measurement set is designed to quantify atmosphere escape rates and provide input to models of the evolution of the martian atmosphere. The NGIMS is designed to measure both surface reactive and inert neutral species and ambient ions along the spacecraft track over the $125-500 \mathrm{~km}$ altitude region utilizing a dual ion source and a quadrupole analyzer.
\end{abstract}

Keywords Mars · Upper atmospheric composition · Mass spectrometry · Atmospheric escape

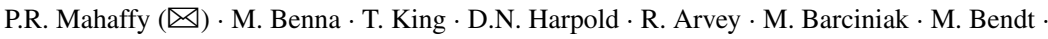

D. Carrigan - T. Errigo · V. Holmes · C.S. Johnson - J. Kellogg · P. Kimvilakani · M. Lefavor ·

J. Hengemihle · F. Jaeger · E. Lyness · J. Maurer - A. Melak · F. Noreiga · M. Noriega · K. Patel ·

B. Prats $\cdot$ E. Raaen $\cdot$ F. Tan $\cdot$ E. Weidner

NASA Goddard Space Flight Center, 8800 Greenbelt Rd., Greenbelt, MD 20771, USA

e-mail: Paul.R.Mahaffy@nasa.gov

C. Gundersen

AMU Engineering, Miami, FL 33156, USA

S. Battel

Battel Engineering, Scottsdale, AZ 85253, USA

B.P. Block · K. Arnett · R. Miller · C. Cooper · C. Edmonson

Space Physics Research Laboratory, University of Michigan, Ann Arbor, MI 48109, USA

J.T. Nolan

Nolan Engineering, Kensington, MD 20895, USA 


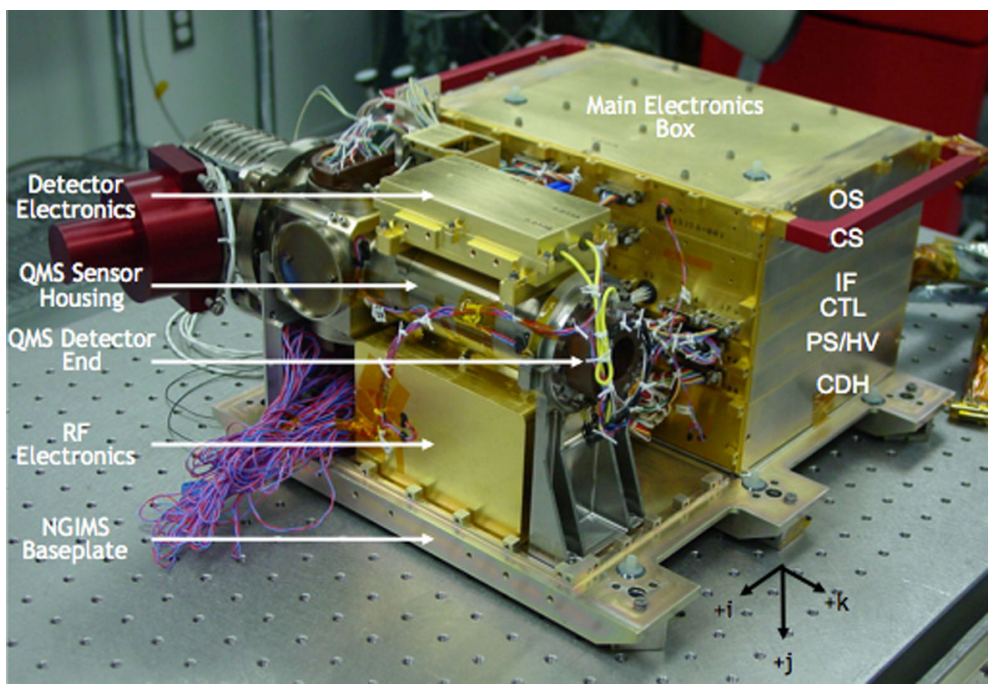

Fig. 1 The NGIMS instrument is shown with the covers removed to show the mass spectrometer and electronics. The Main Electronics Box (MEB) includes the following slices: OS (open source); CS (closed source); IF (interface); CTL (control); PS/HV (power supply and high voltage); and CDH (command and data handling). The red items to be removed before launch are the MEB handles and the break off protective cover. The mass spectrometer in this configuration is sealed in vacuum with a getter to maintain pumping of residual chemically active gases and contains a mixture of noble gases to provide peaks for calibration during integration and testing. The covered break-off cover will be removed at Mars by actuation of a pyrotechnic device to expose the mass spectrometer to the space environment and to release the calibration gases

\section{Scientific Objectives of the MAVEN NGIMS}

\subsection{Exploration of the History of the Martian Atmosphere}

The NGIMS Investigation of the MAVEN mission is designed to contribute to the mission goals to measure the current rate of atmospheric escape to space and its variability with solar input (Jakosky 2014). This data provides input to models of atmospheric loss over time that will enable predictions of past atmospheric pressures and climate. While the surface of Mars is currently cold and dry and the surface pressure less than $1 \%$ and $0.01 \%$ compared to Earth and Venus respectively, liquid water was clearly much more prevalent in the distant past. The NGIMS instrument (Fig. 1) and the other MAVEN instruments provide data that complemented by ongoing and future geological, chemical, and isotopic investigations of ancient surface environments are intended to provide a better knowledge of duration of these potentially habitable surface conditions.

Multiple lines of evidence point toward substantial loss of the martian atmosphere from its earliest history to the present time. Evidence comes not only from in situ measurements but also from extensive studies of meteorites (Bogard and Johnson 1983; Becker and Pepin 1984; Pepin 1985; Wiens and Pepin 1988) that were originally established by a comparison with Viking isotope and composition measurements (Owen et al. 1977; Nier and Mcelroy 1977) to have a martian origin. The fractionation in xenon isotopes revealed in xenon trapped in glassy inclusions in EETA 79001 (e.g. Swindle et al. 1986; Bogard and Garrison 1998) may be the signature of very early hydrodynamic escape (Pepin $1991,1994)$ in a hydrogen rich atmosphere driven by the more intense ultraviolet radiation from the sun in early Mars. Subsequent loss during a period of heavy bombardment 
(Melosh and Vickery 1989) must have removed substantial fractions of the atmosphere as well. The history of the Mars climate and atmosphere from the period when these early loss processes subsided until the present is believed to be a balance between atmospheric loss to space and surface reservoirs and contributions to the atmosphere from volcanic activity and exogenous sources. Escape processes include sputtering (Jakosky et al. 1994), thermal escape, and dissociative recombination (Fox 1993a, 1993b) and loss to the surface by weathering and possibly carbonate formation in liquid bodies. The combined evidence of isotopic measurements of gases trapped in glassy inclusions in ETA89001 and orbital spectroscopic detection of only a few locations of surface carbonates (Ehlmann et al. 2008) point toward the dominance of atmospheric escape compared to a loss to surface reservoirs. Recent in situ measurements from the Curiosity Rover (Mahaffy et al. 2013; Webster et al. 2013a) are consistent with this conclusion with atmospheric values of $\delta^{13} \mathrm{C}$ and $\delta^{18} \mathrm{C}$ in $\mathrm{CO}_{2}$ of $46 \%$ and $48 \%$ respectively (Webster et al. 2013a), ${ }^{36} \mathrm{Ar} /{ }^{38} \mathrm{Ar}$ of 5.2 (Atreya et al. 2013), and D/H in atmospheric water of 5,000\% (relative to Standard Mean Ocean Water-SMOW) (Webster et al. 2013b) all giving enrichment in the atmosphere of the heavier isotope.

\subsection{Previous and Ongoing Measurements of the Upper Atmosphere of Mars}

Neutral mass spectrometers located on the aeroshells of Viking 1 and Viking 2 secured the first detailed measurements of the composition of the upper atmosphere of Mars over the 120-200 km range (Nier and Mcelroy 1976) and reported detection of $\mathrm{CO}_{2}, \mathrm{~N}_{2}, \mathrm{Ar}, \mathrm{CO}$, $\mathrm{O}_{2}, \mathrm{O}$, and NO. These two vertical profiles suggested a well mixed atmosphere and revealed differences in upper atmosphere temperatures with the Viking 2 atmosphere reported to be colder than that measured by Viking 1 . The ${ }^{15} \mathrm{~N} /{ }^{14} \mathrm{~N}$ ratio was reported to be higher than the terrestrial value by $\sim 1.75$. Measurements of the ionospheric species $\mathrm{O}_{2}^{+}, \mathrm{CO}_{2}^{+}, \mathrm{O}^{+}$, $\mathrm{CO}^{+}$, and $\mathrm{N}_{2}^{+}$were secured by the retarding potential analyzers on the Viking aeroshells (Hanson et al. 1977). Additional measurements of ion species relevant to atmospheric loss were secured by instruments on the Phobos spacecraft (Lundin et al. 1990; Verigin et al. 1991). The accelerometer data secured during many months of aerobraking of the Mars Global Surveyor (MGS) satellite that began in late 1997 and the Odyssey satellite that began in 2001 allowed pressures, temperatures, and wave structures to be determined (e.g. Withers 2006) and the response of the atmosphere to variations in solar input and dust loading to be established. MGS radio occultation measurements allowed variations in density and altitude of two electron density peaks centered at $\sim 135$ and $\sim 112 \mathrm{~km}$ to be established (Bougher et al. 2004).

Recent measurements relevant to the study of the upper atmosphere of Mars and atmospheric escape continue to be secured from instruments on the Mars Express spacecraft (Chicarro et al. 2009) which began operation in 2004, notably ASPERA-3 (Analyzer of Space Plasmas and Energetic Neutral Atoms (Lundin et al. 2009)), SPICAM (Spectroscopy for the Investigation of the Characteristics of the Atmosphere of Mars (Bertaux et al. 2009)), MaRS (Mars Express Radio Science Experiment (Pätzold et al. 2009)), and MARSIS (Mars Advanced Radar for Subsurface and Ionospheric Sounding (Plaut et al. 2009)). Two of the Mars Express experiments that most closely match the MAVEN measurements but at a different orbital inclination and periapsis are ASPERA-3 which measures energetic neutral particles, and ion and electron distributions up to energies of $40 \mathrm{keV} / \mathrm{charge}$ (Lundin et al. 2009) and SPICAM which includes ultraviolet and infrared channels and nadir, limb, sun, and star modes of operation. The Mars Express mission has survived long past its nominal mission and there will be synergistic observational opportunities if its instruments are operating during the MAVEN science mission. 


\subsection{Science Goals of the MAVEN NGIMS Investigation}

With more than five orbits each day over the course of the one year nominal mission the goals of the MAVEN NGIMS investigation are to greatly expand on the two detailed profiles of neutral and ion species data secured in this region of the atmosphere in 1976 by the Viking 1 and 2 entry probe aeroshell investigations. This will enable a detailed study of the response of the atmosphere to seasonal dust storms and variations in solar activity. The slow precession of the $75^{\circ}$ inclination orbit will allow periapsis measurements at a range of latitudes and local times. Five one weeklong duration deep dip campaigns over the course of the nominal mission will enable NGIMS measurements over the $\sim 125-500 \mathrm{~km}$ altitude range instead the usual $\sim 150-500$ region of the atmosphere. These deep dips in addition to sampling the well-mixed neutral atmosphere are expected to pass through the peak charged particle region of the ionosphere. NGIMS measurement requirements are to sample the neutral species listed above from the homopause to one scale height above the exobase with a vertical resolution of at least one half scale height for each species. This sampling resolution will enable neutral temperatures to be established from the scale heights.

The NGIMS top level measurement requirements put forward to meet these goals are to

- Establish the structure and composition of the upper neutral atmosphere by securing density profiles of $\mathrm{He}, \mathrm{N}, \mathrm{O}, \mathrm{CO}, \mathrm{N}_{2}, \mathrm{NO}, \mathrm{O}_{2}, \mathrm{Ar}$, and $\mathrm{CO}_{2}$ along the spacecraft track

- Measure isotope ratios such as ${ }^{13} \mathrm{C} /{ }^{12} \mathrm{C},{ }^{18} \mathrm{O} /{ }^{16} \mathrm{O},{ }^{15} \mathrm{~N} /{ }^{14} \mathrm{~N},{ }^{40} \mathrm{Ar} /{ }^{36} \mathrm{Ar},{ }^{38} \mathrm{Ar} /{ }^{36} \mathrm{Ar}$

- Secure profiles of thermal ions $\mathrm{O}_{2}^{+}, \mathrm{CO}_{2}^{+}, \mathrm{NO}^{+}, \mathrm{O}^{+}, \mathrm{CO}^{+}, \mathrm{C}^{+}, \mathrm{N}_{2}^{+}, \mathrm{OH}^{+}$, and $\mathrm{N}^{+}$

\subsection{The NGIMS Measurement Synergy with other MAVEN Investigations}

The Remote-Sensing and Particles and Fields Packages described in the companion manuscripts complement the NGIMS capabilities. The Remote-Sensing Package consists of an Imaging Ultraviolet Spectrometer (IUVS). The Particles and Field Package consists of six individual instruments or instrument sensors designated; Suprathermal and Thermal Ion Composition (STATIC), Solar Wind Electron Analyzer (SWEA); Solar Wind Ion Analyzer (SWIA), Solar Energetic Particles (SEP), Langmuir Probe and Waves (LPW); and Magnetometer (MAG). While overlapping capabilities provide critical redundancies in certain cases, the set of measurements provided by the three packages is designed to secure a full range of energy input and atmospheric parameters to lead to a more precise determination of the rate of atmospheric escape from the planet and its dependence on varying energy inputs from the Sun. For example, the NGIMS team will utilize the LPW (Ergun this issue) determinations of total electron density to establish the total ion density in those cases when ion drifts cause attenuation of the ion flow into the NGIMS. IUVS will secure limb scans near periapsis and disc maps at apoapsis and resolve certain species such as the $\mathrm{D} / \mathrm{H}$ isotope ratio in the upper atmosphere for comparison with the $\mathrm{D} / \mathrm{H}$ in the lower atmosphere recently measured by the SAM instrument (Webster et al. 2013a). The IUVS global maps will complement the NGIMS, LPW, and STATIC measurements taken along the spacecraft track. While the STATIC instrument will measure thermal ions in the same energy range as those sampled by the NGIMS instrument, the unit mass resolution of NGIMS allows it to secure isotope measurements. STATIC measurements that complement NGIMS are the suprathermal ions in the energy range where these ions are escaping, and pick-up ions to energies $20 \mathrm{keV}$ (McFadden et al. 2014, this issue). 


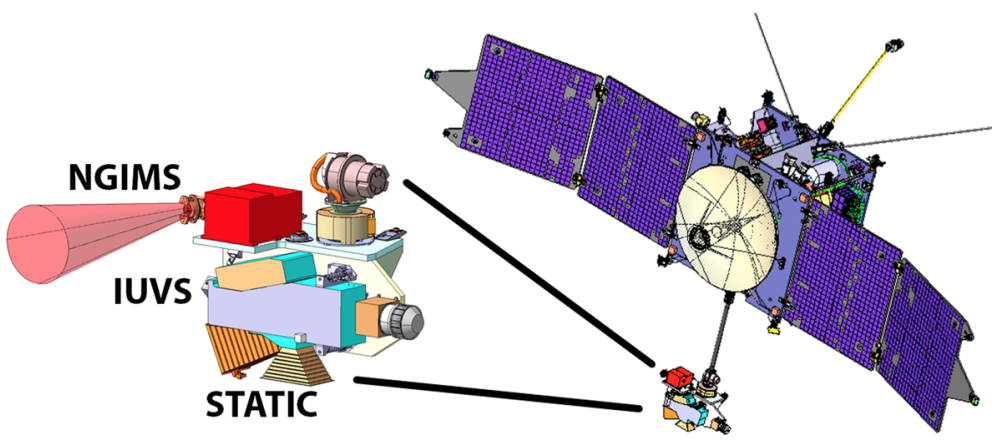

Fig. 2 The APP that will be deployed after the MAVEN spacecraft is in Mars orbit allows pointing of these three instruments independent of the attitude of the spacecraft. This enables the pointing of the solar panels to be optimized for energy management

\subsection{NGIMS Accommodation on the MAVEN Spacecraft}

The NGIMS is mounted (Fig. 2) together with the STATIC and UVS instruments on an Articulated Pointing Platform (APP) that is deployed after arrival at Mars. The APP enables instrument pointing independent of the solar array attitude. This implementation insures a high duty cycling for these three instruments. The optimal attitude for NGIMS is for the axis of the open source to be pointed along the velocity vector of the spacecraft (the RAM direction).

\section{Instrument Description}

\subsection{Introduction and Heritage}

The NGIMS mass spectrometer and control electronics are very similar to the Neutral Mass Spectrometer (NMS) developed in parallel for the Lunar Atmosphere and Dust Explorer (LADEE) mission (Mahaffy et al. 2014). However, most NGIMS elements have a heritage in mass spectrometers previously developed for planetary or Earth orbiting satellites. Although the gas sampling system and ion source were targeted for a particular space environment, the quadrupole mass analyzer and detector systems are similar to those developed for Venus (Niemann et al. 1980), the upper atmosphere of Mars (Niemann et al. 1998), the deep atmosphere of Jupiter (Niemann et al. 1992), and the atmosphere of Ti$\tan$ (Niemann et al. 2002). The immediate predecessors to NGIMS and NMS were the Ion and Neutral Mass Spectrometer (INMS) on the Cassini Orbiter (Kasprzak et al. 1996; Waite et al. 2004) and the CONTOUR (Veverka et al. 1995) Neutral Gas and Ion Mass Spectrometer (CONTOUR-NGIMS) which were modifications of the NGIMS instrument design for the Comet Rendezvous Flyby Mission (CRAF) that say substantial development before that mission was canceled. The CONTOUR NGIMS and the Cassini INMS (Kasprzak et al. 1996) experiments employed an electrostatic 90 degrees deflector (Mahaffy 1990) that could multiplex ions from two sources to the quadrupole analyzer. The instruments developed for CONTOUR, LADEE, and MAVEN were designed to realize substantially greater sensitivity than the Cassini INMS developed at Goddard with nominal sensitivity for nitrogen of $>10^{-3}$ (counts/sec) $/($ part/cc). 
Fig. 3 A schematic of the ion and gas flow into and through the NGIMS

Table 1 NGIMS specifications

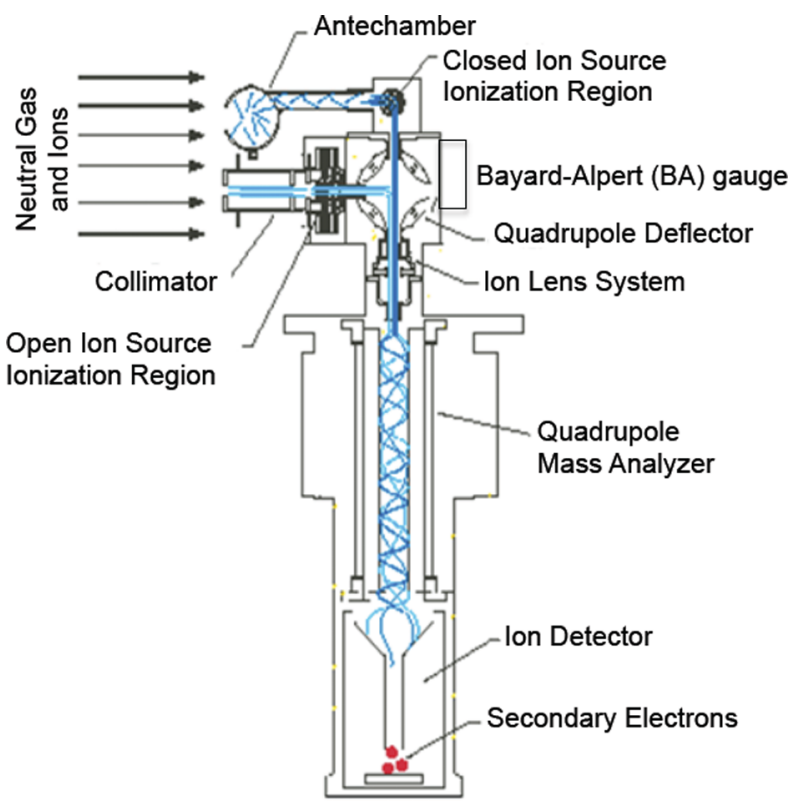

\begin{tabular}{ll}
\hline Neutral gas sampling & $\begin{array}{l}\text { (1) open source/molecular beaming } \\
\text { (2) closed source }\end{array}$ \\
Positive ion sampling & $\begin{array}{l}\text { Thermal and suprathermal through open } \\
\text { source }\end{array}$ \\
Electron beam ionization \\
Ion source & $75 \mathrm{eV}$ \\
Electron energy & $\sim \times 10^{-3}$ counts/sec/part/cc for argon \\
Ion source sensitivity & $2-150 \mathrm{Da}$ \\
Mass range & $\begin{array}{l}\text { Detector pulse counting electron multipliers } \\
\text { (1) neutral gas mode, (2) ion sampling } \\
\text { Detector system } \\
\text { Example scan modes },(3) \text { fractional scan mode in } 0.1 \text { amu } \\
\text { steps } \\
\text { Metal ceramic breakoff cap, pyrotechnically } \\
\text { activated }\end{array}$ \\
\hline
\end{tabular}

NGIMS and the heritage mass spectrometers operate at unit mass resolution over their full spectral range (2-150 Da for NGIMS, 1-99 Da in the case of the Cassini-INMS and 2-294 Da in the case of the CONTOUR-NGIMS). Figure 3 illustrates the elements of the NGIMS while Fig. 4 shows pictures of major elements of the mass spectrometer and its vacuum housing. Several of the instrument performance specifications are given in Table 1. The block diagram (Fig. 5) shows the various electronic subsystems.

\subsection{Neutral Gas and Ion Sampling}

Closed Ion Source The closed ion source was developed early in the history of exploration of the upper atmosphere of the Earth (Spencer and Carignan 1988). It consists of an electron impact hot filament ion source coupled to a largely closed volume where a small aperture in 

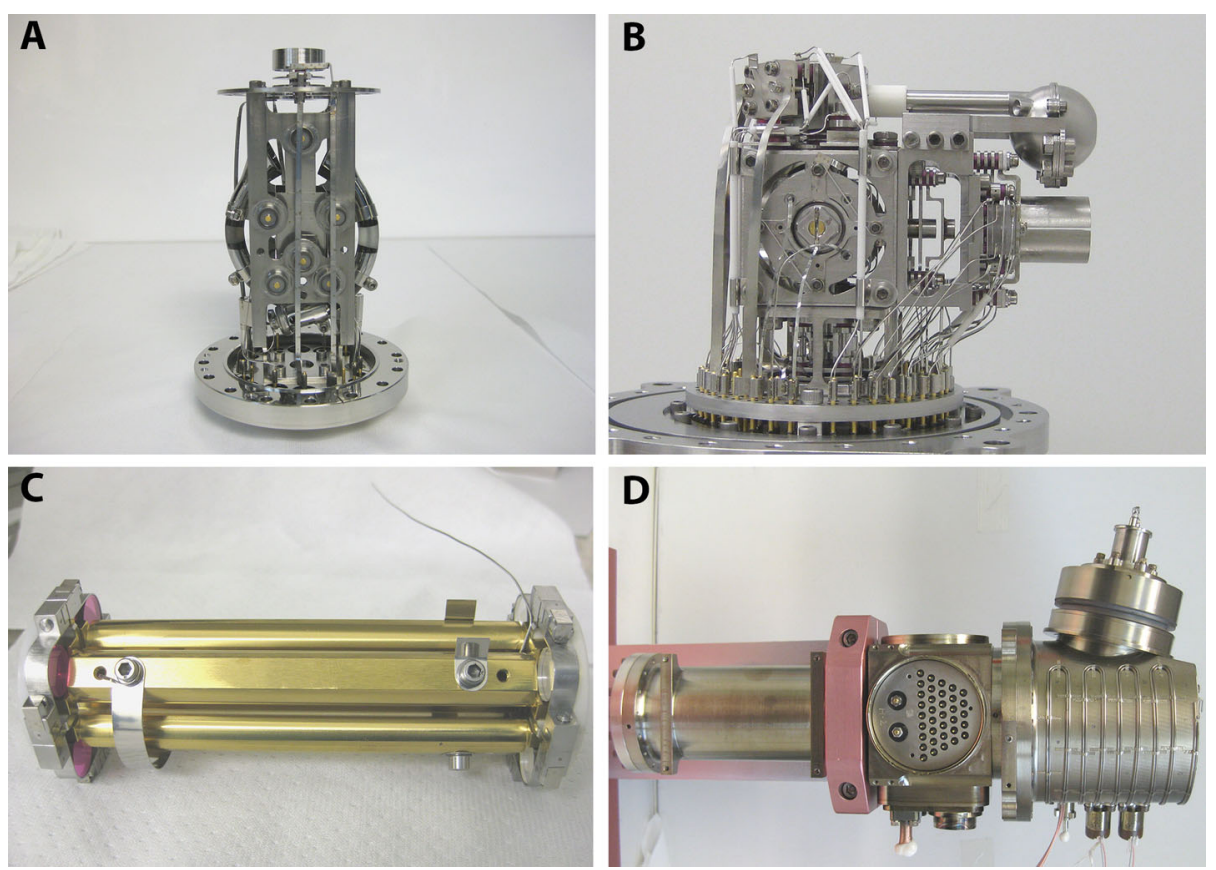

Fig. 4 Major elements of NGIMS include (A) the redundant detector assembly, (B) the dual ion source and focusing lens assembly, (C) the quadrupole rods with opposite rod pair electrical straps shown and the precision ceramic fixture, and (D) the sensor housing with its welded electrical feedthroughs and ion source flanged cover showing the metal to ceramic to metal breakoff cap that is deployed at Mars

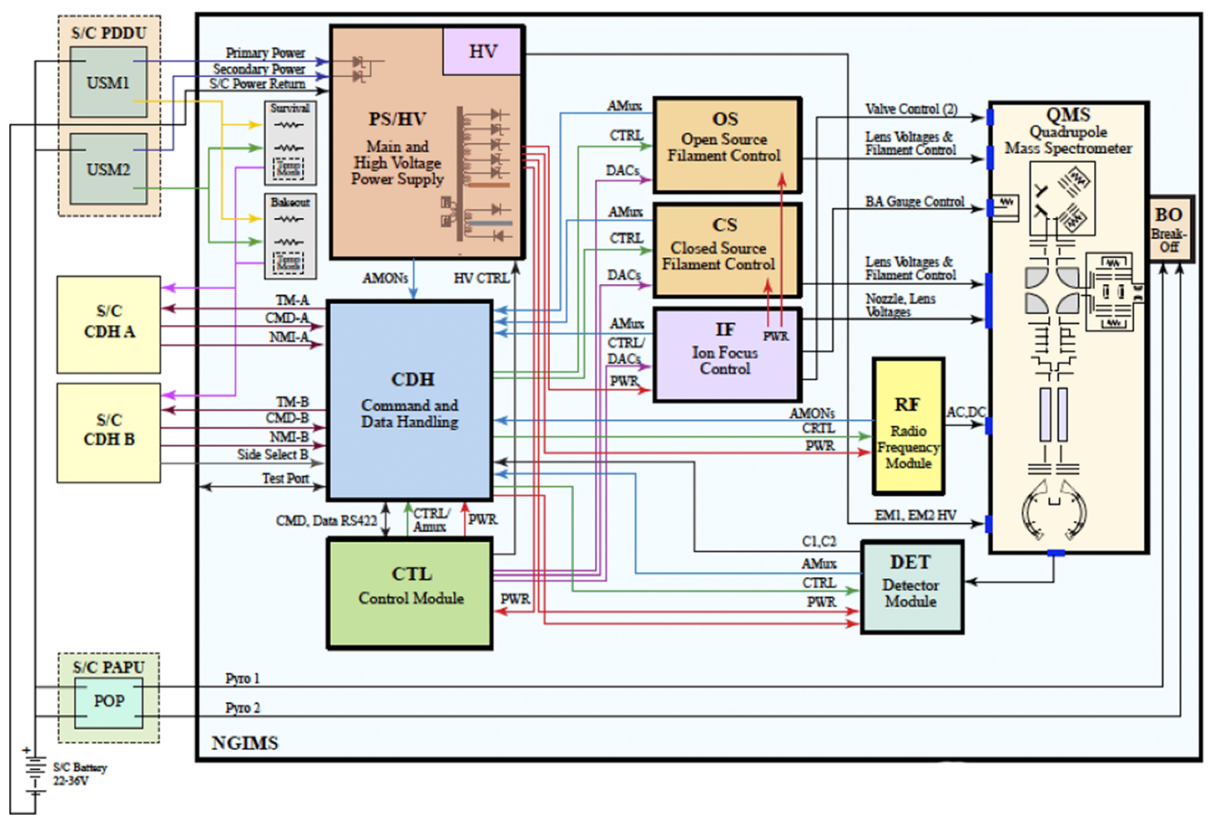

Fig. 5 Electrical block diagram showing the major elements and the redundant data and power interfaces to the NGIMS 
a spherical antechamber samples the ambient atmosphere on an orbiting satellite. Gas flows into the source through this aperture and thermalizes resulting in a mass dependent RAM density enhancement in the source.

Neglecting the small fraction of the gas leaving through the ion exit aperture and other paths out of this volume the density in a closed source of this geometry for species $i$ is (e.g. Wurz et al. 2007):

$$
\begin{gathered}
n_{s, i}=n_{a, i}\left(T_{a, i} / T_{s, i}\right)^{\frac{1}{2}}\left(\exp \left(-S_{i}^{2}\right)+\pi^{\frac{1}{2}} S_{i}\left[1+\operatorname{erf}\left(S_{i}\right)\right]\right) \\
\text { with } S_{i}=V \cos (\alpha) / c_{i} \text { and } c_{i}=\left(2 k T_{a, i} / m_{i}\right)^{\frac{1}{2}}
\end{gathered}
$$

where $n=$ density and $T=$ temperature, with the subscripts $a$ and $s$ designating the ambient and source values respectively for species $i . V$ is the apparent bulk speed of the atmosphere in the spacecraft reference frame, $\alpha=$ the angle between the normal to the orifice and the spacecraft velocity vector, $c_{i}=$ the most probable speed of the ambient gas particles, and $k=$ Boltzmann's constant. The classic closed source configuration will typically accept gas from nearly a $2 \pi$ steradian field of view and will provide nearly a $50 \%$ measurement duty cycle on a spinning spacecraft. The MAVEN spacecraft is 3-axis stabilized during the NGIMS measurement periods.

Open Ion Source The open ion source measures species such as $\mathrm{O}$ and $\mathrm{N}$ that are destroyed or transformed by collisions in the closed ion source. In the open ion source, collimating apertures form a neutral beam of particles that pass through a crossed electron beam generated by focusing electrons emitted from a hot, $97 \%$ tungsten, $3 \%$ rhenium, 0.005", 6-coil filament. A fraction of these particles are ionized and transported through the electrostatic deflector to the quadrupole analyzer and the pulse counting detector. Thermalized ions can be partially rejected by the bias on a partially transparent metal grid that repels the lower energy thermalized ions created in the electron beam source. At a spacecraft velocity of $4.15 \mathrm{~km} / \mathrm{sec}$ and a resulting $0.89 \mathrm{eV} / \mathrm{amu}$ in the instrument frame of reference, the heavier thermalized ions can be rejected efficiently by this method and the lighter ions such as $\mathrm{He}+$ less efficiently. Ambient ions are swept out of the inlet path by a set of deflection electrodes before they reach the ionization region.

The electrostatic deflector is an energy dispersive device. The bandpass of the deflector is approximately $25 \mathrm{eV}$ with the voltages selected for the NGIMS operation. This bandpass limits the energy of ions sampled by the instrument in its ambient ion measurement mode. The efficiency of the open source for neutral gas in the ionization region is nearly the same as the closed source but without the RAM enhancement realized in the closed source.

\subsection{Quadrupole Mass Analyzer and Detector}

Quadrupole Mass Filter The mass analyzer (Fig. 4C) consists of four hyperbolic quadrupole rods precisely fabricated and assembled into a rigid parallel assembly to which a combination of radio frequency (RF) and static (DC) voltages are applied to achieve mass separation. The voltages $\left(V_{d c}+V_{a c} \cos (\omega t)\right)$ and $-\left(V_{d c}+V_{a c} \cos (\omega t)\right)$, where $\omega$ is the frequency of $V_{a c}$, are applied to opposite rod pairs resulting in a two-dimensional quadrupole field of the form

$$
\varphi(x, y)=\left(V_{d c}+V_{a c} \cos (\omega t)\right)\left(x^{2}-y^{2}\right) / R_{o}^{2}
$$

where $R_{o}$ is the distance from the $z$ (symmetry) axis to the nearest rod surface, and $x$ and $y$ are the axes crossing both the $z$ axis and nearest point of the adjacent rods. Two fixed 
frequencies were used over the 2-150 Da mass range of NGIMS: $3.0 \mathrm{MHz}$ for the mass range 2 to $19.5 \mathrm{Da}$ and $1.4 \mathrm{MHz}$ for the range 19.5 to $150.5 \mathrm{Da}$. Small amplitude changes in the RF are made under software control to compensate for any temperature or frequency drifts. These corrections keep the analyzer tuning quite constant over the instrument operating temperature range of $-20 \mathrm{C}$ to $+40 \mathrm{C}$.

The $V_{d c}$ has an additional bias voltage, $V_{\text {bias }}$, added to it that is a function of the mass. This voltage is adjusted during tuning to allow ions to spend sufficient time (cycles) in the mass resolving RF field thus reducing the mass peak width and hence increasing the mass resolution.

Detector Assembly The NGIMS detector assembly consists of a system of ion focusing lenses and two redundant off-axis continuous channel electron multipliers. The ion focusing lens system consists of four lenses positioned between the exit of the quadrupole analyzer and the entrance of the multipliers. A voltage ranging from $-200 \mathrm{~V}$ to $550 \mathrm{~V}$ is applied to each lens to focus the ions exiting the analyzer into the detectors.

The Photonis model 4870-channeltron electron multipliers were assembled at Goddard onto a custom designed support frame. Finite element analysis was employed in the design of the detector frame to insure that these glass devices would not be damaged during the considerable vibrations incurred during the MAVEN launch and the martian orbit insertion burn. The NGIMS multipliers saturate at several million counts per second with an average gain of $\sim 5 \times 10^{7}$, and a background noise of less than 1 count per minute. The operating voltage is between $-2400 \mathrm{~V}$ and $-3000 \mathrm{~V}$. The two multipliers are assembled facing each other within their housing, providing a redundant system. The multipliers are positioned off axis of the quadrupole to avoid detecting spurious photons and neutrals.

\subsection{Calibration Reservoir}

In order to track possible long term changes in sensitivity NGIMS incorporates a calibration gas reservoir that will be used occasionally in flight to assess the instrument response. The calibration gases are equal parts of $\mathrm{N}_{2}, \mathrm{CO}_{2}, \mathrm{Ar}, \mathrm{Kr}$, and Xe to establish the response of the instrument over much of its mass range. Use of $\mathrm{N}_{2}$ and $\mathrm{CO}_{2}$ will serve another purpose to establish calibration factors for two gases that were difficult to calibrate just prior to instrument pinch off because of the close proximity of the getter to the ionization region. The getter on NGIMS is incorporated in the break-off cap and will be removed from the instrument once this cap flies off into space. The calibration reservoir is sealed behind two microvalves of SAM heritage to insure that no residual gas will enter the mass spectrometer during measurement times below $500 \mathrm{~km}$. Calibration will be carried out at an interval of several weeks near apoapsis by opening both valves which establishes a restricted flow through a capillary leak into the closed source of NGIMS. The capillary leak consists of 7-12 micron capillaries that in parallel establish a pressure of $1 \times 10^{-6}$ Torr in the ion source.

\subsection{Electrical Design}

Spacecraft Interface The NGIMS Main Power is supplied via a redundant, spacecraftswitched, 3 A resettable circuit breaker operating at the nominal spacecraft bus voltage of $28 \mathrm{~V} \mathrm{DC}$ with an operating range of $22 \mathrm{~V}$ DC to $36 \mathrm{~V}$ DC. NGIMS has 3 heater circuits: Bakeout, HTR1 and HTR2 heaters. The HTR1 and HTR2 power are supplied by the spacecraft power bus via single-string, spacecraft-switched, 2 A resettable circuit breakers. The Bakeout Heater is a redundant spacecraft-switched, 2 A resettable circuit breaker operating 
at the nominal spacecraft bus voltage of $28 \mathrm{~V} \mathrm{DC}$. Any, or all, buses may be turned on in any order and the maximum possible power from all busses is approximately $50 \mathrm{~W}$. Power usage during experiment operation is a function of the commanded instrument mode with the power sequencing on $30 \mathrm{~ms}$ intervals. The spacecraft also provides four switches for arming and firing the two bellow actuators in the break-off cap. These switches serve as the Arm and Fire commands for each pyro. The spacecraft Interface includes monitoring capability for six (6) Platinum Resistive Thermometer (PRT) temperature sensors.

The spacecraft Data Interface consists of a redundant (A and B side), high speed ( $2 \mathrm{Mb} / \mathrm{s}$ ) with side select along with a discrete interface (NMI) used for interface reset if needed.

NGIMS Module Overview Most of the NGIMS instrument electronics are integrated into the Main Electronics Box (MEB) as 6 slices or modules. The list below is in the order they are incorporated as slices into the MEB.

- PS/HV_-Power Supply/High Voltage

- $\mathrm{CDH}-$ Command Data Handling

- CTL-Control

- IF- Ion Focus

- CS-Closed Source

- OS-Open Source

The two stand-alone modules are the RF (Radio Frequency) and DET (Detector) which are both attached to the Quadrupole Mass Sensor (QMS) housing. With exception of the survival and bakeout heaters, all of the modules receive their power from the common NGIMS power supply.

Power Supply/High Voltage (PS/HV) Module The PS/HV Module utilizes a two stage design that provides good line and load regulation without post-regulators and provides primary and secondary isolation. A Pulse Width Modulator (PWM) pre-regulator operating at $50 \mathrm{kHz}$ feeds a $75 \mathrm{~W}$ DC-DC converter (slaved to the $50 \mathrm{kHz}$ oscillator) providing six independent ground-isolated secondaries (DC and AC outputs). Load regulation is better than $5 \%$ over expected load and temperature conditions and the power supply operates within specification over an input voltage range of $22 \mathrm{~V} \mathrm{DC}$ to $36 \mathrm{~V} \mathrm{DC}$.

Other features include filter pre-charging and soft-start control to limit inrush current, EMI filtering with a common-mode Balun, under-voltage detection, primary side power monitoring, input power limiting, and auto restart from a fault condition. Two high voltage (HV) supplies are integrated into the module providing two DAC programmable outputs up to $-3500 \mathrm{~V}$ DC for the Channel Electron Multipliers (CEMs).

Command and Data Handling ( $\mathrm{CDH}$ ) Module The NGIMS Command and Data Handling module $(\mathrm{CDH})$ is based on a radiation hardened, 32-bit Coldfire microprocessor. The module contains 2 megabytes of rad-hard static RAM (SRAM) memory, 32 kilobytes of PROM and 1 megabyte of Electrically Erasable PROM (EEPROM). The PROM memory contains a non-changeable bootloader which allows NGIMS to update the main flight software application stored in the EEPROM memory. In addition, tables and scripts are uploaded into the EEPROM as required. The SRAM memory is used to run the flight software, which controls operation of the NGIMS instrument, and for temporary data storage.

In addition to providing the computer controller for NGIMS, the CDH module also contains two 16-bit analog to digital converters (ADC) for sampling various housekeeping parameters within the system, such as voltages, currents and temperatures. A master AMUX is 
used to multiplex 152 channels of analog data to these two ADCs. Fifteen digital to analog converters (DACs) are provided for controlling the NGIMS filaments and the RF subsystem. Two additional DACs are employed for setting the threshold for pulse counters. The CDH module communicates with the MAVEN spacecraft via a synchronous 422 serial command and telemetry bus along with a discrete interface (NMI). All data collected by NGIMS is packetized by the flight software and sent to the MAVEN spacecraft via this interface. The time of acquisition of any element of housekeeping data can be established relative to any detector count data.

Control Electronics (CTL) Module The Control module (CTL) provides twenty-eight 8bit, thirty-eight 12-bit and two 16-bit digital to analog converters. These devices are used to control the Open Source (OS), Closed Source (CS) and Ion Focus (IF) electronics that in turn control the higher voltages required by the QMS. All of the DACs are controlled by the flight software running on the $\mathrm{CDH}$ and are synchronized with the operations of the $\mathrm{CDH}$ hardware. Additionally, the CTL module provides local low-voltage regulation for the CTL, $\mathrm{CDH}$ and DET modules.

Ion Focus (IF) Module The IF module contains electronics to operate the Bayard-Alpert (BA) gauge pressure sensor and provides DAC controlled electrode bias functions for the Quadrupole Mass Spectrometer. The BA gauge filament is controlled by a single voltage loop under DAC control and does not have direct emission regulation. The BA gauge was used as a safety check to establish the internal sensor pressure before turning on the QMS filament during environmental tests and in cruise. As part of the BA measurement circuit, the filament is biased at $+20 \mathrm{~V} \mathrm{DC}$ using a virtual ground configuration to allow a direct emission current measurement, up to $1 \mathrm{~mA}$. $+160 \mathrm{~V}$ DC bias for the Grid and an electrometer capability are also provided in order to make the pressure measurement.

The IF module also provides DC voltage supplies for the IF, CS, and OS highvoltage amplifiers. Nineteen DAC controlled amplifiers on the IF provide the biases required by the QMS for proper focusing, including eight $-900 \mathrm{~V} \mathrm{DC}$ and one $+900 \mathrm{~V}$ DC outputs. The error amplifier drive for each electrode is monitored in the housekeeping data such that a short to structure or to another electrode can be determined from the telemetry. Two valves are also controlled by the IF Module.

Open Source and Closed Source (OS/CS) Modules The OS/CS consists of two modules dedicated to filament emission control and electrode bias functions for the QMS Open and Closed Ion Sources. Each ion source contains two filaments that are not operated simultaneously. A linear pre-regulator with an independent control loop is employed to minimize the effects of line and load variations on the emission current. Two DACs are utilized for ion source operation; one to control filament voltage and the second to set emission current. This allows the flight software to soft start the filament by creeping up the filament voltage until the stable emission operating point is reached. The emission control level is programmable from $20 \mu \mathrm{A}$ to $400 \mu \mathrm{A}$ with control normally set to either 50 or $250 \mu \mathrm{A}$. A unique feature of the emission control loop design is that the filament floats at $-70 \mathrm{~V} \mathrm{DC}$ using a virtual ground configuration to allow direct measurement of the emission current. A latching relay sets the bias voltage on the active filament with the inactive filament referenced to ground. Each module provides 18 DAC settable bias voltages ranging from -300 volts to +300 volts for the QMS focusing electrodes in order to properly focus the electrons and ions. The electrode voltages are regulated to $2 \%$ absolute and $0.5 \%$ relative accuracy. 
RF Electronics The MAVEN NGIMS RF Electronic Subsystem primary function is to provide two selectable and stable AC frequencies to the Quadrupole Rods of the NGIMS instrument. The amplitude of the DC and RF voltages provided to the QMS rods is controlled by the analog output of 16 bit DACs located in the $\mathrm{CDH}$. The RF tuning requires an unusually high accuracy and stability. For example, a 1/10th Da shift can result from an amplitude change of $0.03 \%$ or a frequency change of $0.015 \%$. This sensitivity requires tight requirements for the stability of these open loop analog circuits over the wide temperatures that this circuit is required to operate under. A tank circuit Q above 120 is required to achieve low power $(8 \mathrm{~W})$ and high voltage $(1200 \mathrm{~V} \mathrm{p}-\mathrm{p})$, and the necessary frequency stability.

The frequencies are defined as High Frequency (HF) $3.0 \mathrm{MHz}(+/-0.3 \mathrm{MHz})$ corresponding to 2-19.5 Da and Low Frequency (LF) $1.4 \mathrm{MHz}(+/-0.1 \mathrm{MHz})$ corresponding to $\sim 19.5-150.5 \mathrm{Da}$. The dynamic range is linear from $50 \mathrm{~V}$ p-p to $700 \mathrm{~V}$ p-p for HF and $50 \mathrm{~V}$ p-p to $1200 \mathrm{~V}$ p-p for LF. The AC waveform stability is such that mass peaks are stable to $+/-2 \%$ over a temperature range of $-20^{\circ} \mathrm{C}$ to $+45^{\circ} \mathrm{C}$.

The two ROD+ and ROD- outputs are 180 degrees out of phase and have controllable and inverted DC biases of up to $+/-150 \mathrm{~V}$ DC. There is also a controllable DC offset Quad Bias voltage of $+11 \mathrm{~V} \mathrm{DC}$ to $-10 \mathrm{~V}$ DC that float both outputs. Total RF power required is under $8 \mathrm{~W}$ peak and $4 \mathrm{~W}$ average. The time required to reach a nominal mass value (within + or -0.1 AMU) in a different frequency range is well under 20 milliseconds.

DET Electronics The NGIMS detection system consists of redundant Photonis Channel Electron Multipliers. The DET electronics provides independent amplification and discrimination for each multiplier. Each channel is identical providing about $36 \mathrm{~dB}$ of gain and roughly $500 \mathrm{MHz}$ performance to reduce dead time contributions from electronics. The entire assembly consumes about $1.2 \mathrm{~W}$ of power.

\subsection{Flight Software and Scan Sequences}

The elements of the flight software used by the NGIMS Coldfire processor are listed below. The software can be loaded into SRAM either from the spacecraft or from the NGIMS EEPROM. The flight software is fully uploadable and modifiable safely in flight.

PROM Boot Loader When power is applied to the NGIMS the boot loader gains control. If no commands are received from the spacecraft interface within 30 seconds it begins to load the operational image from EEPROM. After this load is finished control is transferred to its entry point. If a command is received within the first 30-second interval after power up the boot loader waits for further commands. The boot loader has a command set that enables it to maintain the EEPROM file system by creating, modifying, copying, moving, or deleting files. The boot loader can also erase and reformat the EEPROM. It can also mark bad blocks and select among operational image files for booting. After the boot loader carries out the chip-level and board-level initialization it enters a background loop and listens for command with the only exit from this lop being via a program load operation. The boot loader operates in safe mode with no operating system or interrupts.

EEPROM File System The parameter tables, script files, and other data as well as the operational software image are stored in this non-volatile memory. The EEPROM file system was taken entirely from the flat file system designed for the SAM suite. Redundant directories located at the high and low end of the memories employ automatic fail-over and are protected by checksums. Both the boot loader and the operational image can access the 
EEPROM file system. Each file created in EEPROM is assigned a unique ID number, an assignable type code, and a file checksum computed when the file is written. These files occupy contiguous blocks of memory and the checksum is stored in the file's directory entry. Files cannot be used unless the checksum in the directory matches that computed from the file. The message log telemetry includes the ID, checksum, type, and name for each file.

Script Processor This command system was also taken entirely from the SAM design and consists of a BASIC interpreter that employs the full set of language constructs, such as FOR-NEXT, DO-LOOP, IF-ELSE-ENDIF, and nested subroutine calls. It also employs unique built-in commands to operate the instrument in all its various modes. Functions or subroutines can be defined that contain multiple lines of BASIC script that can take arguments or parameters and may return a value. These functions called by name are the building blocks of the NGIMS experimental sequences that will typically operate in orbit around Mars. The script processor developed for the Mars Science Laboratory SAM experiment on which the NGIMS script processor is based has been more fully described (Mahaffy et al. 2012).

Alarm Monitoring A background process in the flight software continuously checks housekeeping values (currents and temperatures) for out-of-limit conditions. The process is table-driven. The limits are read in from a parameter table in EEPROM, and can be modified by script command, allowing modal dependencies. The alarm monitor is integrated with the script processor. The response to any out-of-limit condition is the immediate execution of a script, which is identified in the limit table, and can be customized to the particular condition. The script can cause the instrument to shut down and await ground intervention, or to resume operations if that can be done safely.

Scan Sequences The flight software implements several methods to control the QMS scanning sequence, which are invoked through script commands as originally developed for SAM. For NGIMS, the nominal sequence breaks the $<500 \mathrm{~km}$ orbital science into $10 \mathrm{se}-$ quentially exercised phases. For each phase the script cycles through a table that selects a set of $m / z$ values and the ion source or sources to be employed together with any DAC values selected to attenuate the signal if necessary to avoid detector saturation. This allows measurements to be tailored to the anticipated conditions at every orbital position, thereby increasing spatial resolution and signal strength for less abundant species that require greater integration time. Known or expected species will be tracked with sufficient time resolution to establish scale height temperatures and mass ranges where signal is not expected will be sampled on a more occasional basis. Scans at 1/10 amu resolution will be employed before and after each low altitude pass to track instrument backgrounds. The core measurement script will allow lens scans or detector voltage scans to be included as desired to establish instrument health. The calibration script will not be part of this regular science script but will be exercised on a regular basis over the course of the mission to evaluate any long-term changes in instrument performance. The instrument will remain in standby mode above $500 \mathrm{~km}$ and ion source filaments may be commanded on for increased fractions of the MAVEN orbit if is necessary to further stabilize the instrument backgrounds.

\subsection{Mechanical Configuration}

Design Process The design software tool ProE was used throughout this development for all mechanical elements of NGIMS. Prior to fabrication, stress and modal analysis was performed on the housing structure assembly. The finite element model was created in the finite 
element application FEMAP and processed in Nastran. The parts of structure analyzed were the housing base, the external and internal structural panels, the sensor support bracket, and various fasteners and mounting hardware. The outcome of this analysis was that the fundamental frequency was found to exhibit positive safety margins for maximum stress in the assembly and for all fastening hardware in tension and shear.

Pyrotechnic Breakoff The pyrotechnic operation that exposes the ion source system to the space environment is scheduled during the commissioning phase of the mission. The MAVEN spacecraft provides the high current actuation pulse for this pyrotechnic device. Since the sensor was baked to nearly $300{ }^{\circ} \mathrm{C}$ several times, the breakoff cap is designed to be ultra-high-vacuum compatible and consists of an external wedge that upon actuation by a pyrotechnic device, breaks a metal to ceramic to metal seal. Spring loading on the breakoff cap sends this cover away from the spacecraft and the instrument after actuation. The apertures exposed to space those of the closed and open source as illustrated in Figs. 3 and 4.

\subsection{Thermal Design}

The NGIMS has a passive thermal design dissipating all internal power using Silver Teflon coated radiators on three sides of the Main Electronics Box (MEB) and one of the enclosure panels around the Quadrupole Mass Spectrometer (QMS) Assembly. The rest of the instrument is covered in Germanium Black Kapton MLI blankets except for the entrance apertures and titanium shield that is exposed when the break-off cap is ejected after Mars orbit insertion. The instrument is conductively isolated from the APP on 6 titanium flexures. The MEB consists of 6 aluminum frames (known as slices) with an electronics board mounted to each. The six slices are then bolted together and to the instrument base plate. The majority of the internal power dissipation is in the MEB with additional power dissipated in the RF housing, the detector housing and the filaments in the ion source of the QMS assembly.

The nominal science orbit is approximately 4.5 hours. The operating temperature range for the majority of the instrument is $\left(-20^{\circ} \mathrm{C}\right.$ to $\left.+50{ }^{\circ} \mathrm{C}\right)$. NGIMS is intended to be in standby mode $(20 \mathrm{~W})$ for the majority of the orbit and only be in science mode $(40 \mathrm{~W})$ for 24 minutes centered on periapsis with a maximum one hour filament warm-up and calibration period $(37 \mathrm{~W})$ prior to science mode. During the deep dip campaigns, periapsis drops from a nominal $150-500 \mathrm{~km}$ to $125 \mathrm{~km}$ where aero heating contributes to heating of the RAM surfaces (modeled as constant 10 minutes of additional $0.065 \mathrm{~W} / \mathrm{cm}^{2}$ ).

There are two additional modes of operation; survival and decontamination. During survival $\left(-30{ }^{\circ} \mathrm{C}\right.$ to $\left.+65^{\circ} \mathrm{C}\right)$, the NGIMS is powered down and the temperature is maintained with spacecraft operated survival Kapton strip heaters on the Base Plate. If warranted the NGIMS can be placed in a decontamination mode where the Ion Source Cover is heated up to $180^{\circ} \mathrm{C}$ with Inconel sheathed flexible heaters to remove accumulated contaminants on the inlet. The aero heating and decontamination mode temperatures resulted in an all Kapton MLI design (no Dacron netting) and selective taping to eliminate possible adhesive contamination or failure due to high temperatures.

\subsection{GSE}

GSE Overview The ground support equipment (GSE) is designed to enable test and calibration on individual components of the NGIMS instrument and on the instrument as a whole. Computer-controlled non-flight electronics provides voltages to all the NGIMS electrodes and the electron gun emission control. This GSE was used to tune and calibrate the 
quadrupole mass spectrometer (QMS) prior to integration of the QMS with the main electronics board (MEB). Other GSE was developed to test the MEB and the flight software. The software team created simulators to generate data so that the electronics could be tested without a QMS present.

Two primary software applications perform the control and analysis functions. The "MAVENGSE" application sends commands and to the instrument and receives the telemetry stream. The "MAVENDataView" application allows the operator to view the telemetry data in graphs and tables either in real-time as the data arrives, or to review previously recorded data. Both applications were used during rack testing are still in use for operations.

The GSE was adapted from similar systems developed for SAM and other programs. Nearly identical GSE was used for the development of the LADEE NMS. The configuration of the GSE evolved as the instrument development phase moved from the early stages of testing and optimization to calibration then environmental qualification and finally to operation after integration with the spacecraft.

Electronics GSE This rack generates signals required to operate the mass spectrometer including all of the high voltage lenses, the high voltage electron multipliers and the regulated current to the filaments. Pulse counters in the rack read the detector signal. Custom software on a Linux-based workstation operates the mass spectrometer to allow lens tuning and instrument calibration.

Mechanical GSE This consists of the calibration chamber with associated pressure monitors and a gas manifold. The ultra-high-vacuum system provides continuous vacuum pumping to maintain an ultra-high-vacuum base pressures of less than $1 \times 10^{-10}$ Torr. The gas manifold and associated pressure monitors allows the introduction of calibration gases at controlled pressures.

Spacecraft and Instrument Simulators The spacecraft simulator consists of a set of circuits in a USB-connected laptop-controlled box that provides power and commanding and communication to the NGIMS instrument equivalent to that provided by the spacecraft. This system was used during qualification and environmental testing and after the NGIMS had been delivered to the spacecraft bus prior to integration.

NGIMS flight software commands are sent from the GSE computer to the simulator through a TCP connection. The simulator converts the commands to the high-speed serial bus that is used aboard the spacecraft. Telemetry from NGIMS is received by the simulator and passed through via the TCP port to the GSE data viewer application.

The QMS simulator generates artificial mass spectra that allow the NGIMS flight software to react as if it were acquiring real data. This provides high fidelity testing of flight software and flight scripts as well as verifying end-to-end functionality of software tools. An ideal perfect mass spectrum can be generated and verified to pass through the instrument and to the analysis tools unchanged.

\section{Instrument Qualification}

\subsection{Environmental Testing}

The integrated MAVENNGIMS instrument was subjected to a full environmental test campaign to demonstrate instrument performance at the anticipated launch and science conditions for the MAVEN mission. All tests were conducted to proto-flight levels. 
Table 2 EMI/EMC Tests Conducted on the NGIMS

\begin{tabular}{lll}
\hline Test ID & Type & Frequency range \\
\hline CE01 & Power Leads & $30 \mathrm{~Hz}-100 \mathrm{MHz}$ \\
CE03 & Power Leads & $30 \mathrm{~Hz}-50 \mathrm{MHz}$ \\
CMCE & Power \& Signal Leads & $30 \mathrm{~Hz}-200 \mathrm{MHz}$ \\
CE Structure & Structure Current & - \\
CS101 & Power Leads & $30 \mathrm{~Hz}-150 \mathrm{kHz}$ \\
CS02 & Power Leads & $150 \mathrm{kHz}-50 \mathrm{MHz}$ \\
CS114/115 & Power \& Signal Leads, & $150 \mathrm{kHz}-200 \mathrm{MHz}$ \\
& Bulk Cable Injection & \\
RE102 & E-Field & $10 \mathrm{kHz}-18 \mathrm{GHz}$ \\
RS103 & E-Field & $14 \mathrm{kHz}-10 \mathrm{GHz}$ \\
In-Rush Current & Turn-on Transient & - \\
& Analysis & \\
\hline
\end{tabular}

EMI/EMC Test An electromagnetic interference and compatibility (EMI/EMC) test was performed at the GSFC EMI/EMC Test Facility to characterize possible interference sources emanating from NGIMS as well as identifying any vulnerabilities in both a conducted and radiated configuration. The specific EMI/EMC tests are summarized in Table 2. The tests were conducted in accordance with the standard MIL-STD-461F.

Conducted emissions testing (CE01, CE02, CMCE) measured the levels of NGIMS narrowband conducted emissions over the NGIMS power and signal leads. In CE01, the NGIMS primary power leads satisfied all test criteria across the entire frequency range. However, the NGIMS secondary power leads exhibited exceedances at three frequencies: $40 \mathrm{~Hz} / 20 \mathrm{~dB}, 70 \mathrm{~Hz} / 11 \mathrm{~dB}, 105 \mathrm{~Hz} / 1 \mathrm{~dB}$. Subsequent analysis of the NGIMS location on the Articulated Payload Platform and consideration of the low MAVEN spacecraft bus impedance demonstrated that the measured exceedances were acceptable for flight. In CE03 testing, the NGIMS exhibited emissions above the prescribed limits within a frequency range of $14 \mathrm{kHz}-4 \mathrm{MHz}$ ). These exceedances were deemed acceptable by the MAVEN Project given that the MAVEN observatory does not have any receivers within this frequency range that require protection. The NGIMS instrument met all test criteria for CMCE testing.

The NGIMS structure current between the NGIMS chassis to ground and the in-rush current was within limits however the settling time of $60 \mathrm{~ms}$ exceeded the requirement of $20 \mathrm{~ms}$. The requirement on settling time was subsequently waived by the MAVEN Project for all payloads to a less stringent standard.

Conducted susceptibility testing (CS02, CS101, CS114, CS115) was performed to ascertain degradation in NGIMS performance when exposed to conducted RF. Test results for CS02 show that NGIMS exhibited susceptibility above $0.3 \mathrm{~V} \mathrm{rms}$, peaking at $16.5435 \mathrm{MHz}$. No susceptibility or performance degradation was detected above $25 \mathrm{MHz}$. Given the stability of the MAVEN spacecraft bus voltage is typically much less than a few millivolts, the likelihood of conducted RF signals injected into the NGIMS power and signal leads above $100 \mathrm{mV}$ range is very low. Thus NGIMS meets the MAVEN requirements for CS02. Test results for CS101, CS114 and CS115 demonstrate that NGIMS met and passed all test requirements.

A radiated emissions test (RE102) was performed to measure the levels of narrowband radiated emissions emanating from NGIMS or associated cable harnesses between $10 \mathrm{kHz}-$ $18 \mathrm{GHz}$. After adding electrical shielding around the non-flight test power cables to more accurately represent the flight configuration, the NGIMS instrument was shown to meet 
all RE102 test requirements except for exceedances within the Electra Relay band (350$490 \mathrm{MHz}$ ) with a max of $17 \mathrm{~dB}$ at $400 \mathrm{MHz}$. As NGIMS is not planned to be in science mode during Electra relay passes, if high emission levels persist on orbit, NGIMS will be turned off with minimal consequences.

Radiated susceptibility testing (RS103) was performed to characterize degradation in NGIMS performance when irradiated at various frequencies. The NGIMS instrument was not susceptible to electric fields in the range of $14 \mathrm{kHz}-10 \mathrm{GHz}$.

Random Vibration Test The flight NGIMS was tested to the proto-flight random, sinusoidal, and sine burst vibration levels as defined by the anticipated MAVEN mission loads environment. Testing was performed at the Goddard Space Flight Center (GSFC) Vibration Test Lab. Eighteen accelerometers were attached to the instrument in order to monitor the acceleration responses during testing.

During testing the instrument was double bagged in order to protect it from contamination. Additionally, a nitrogen gas flow was established into the inner bag in order to create a positive pressure in the bag to prevent contamination and maintain low humidity within the bag. Testing was performed with the flight Breakoff Assembly (with inert burn wires instead of live pyros) installed and a safe plug installed on the pyro firing circuit as well as with connector savers and ESD caps attached to the power, signal and heater connectors.

The test sequence conducted on each of the three instrument axes was as follows: Comprehensive Performance Test (CPT), low level sine signature sweep (5-2000 Hz, $0.1 \mathrm{~g}$ ), sine burst ( $\frac{1}{4}$ level, $\frac{1}{2}$ level, full level 5 cycles, $\left.20 \mathrm{~Hz}, 16.3 \mathrm{~g}\right)$, random proto-flight vibe $(-12 \mathrm{~dB}$, $-9 \mathrm{~dB},-6 \mathrm{~dB},-3 \mathrm{~dB}$, full level 9.59 grms), low level sine signature sweep (5-2000 Hz, $0.1 \mathrm{~g}), \mathrm{CPT}$. No frequency notching was required.

The test met the success criteria with visual inspection, pre and post-test sine sweep signatures showing less than a $5 \%$ shift in frequency, and successful completion of the between-axis CPT and the post-vibration functional tests.

Thermal Balance and Thermal Vacuum Tests The NGIMS instrument was configured with flight thermal blankets and underwent a thermal balance test to validate the NGIMS thermal model which is used to generate temperature predictions during different phases of the MAVEN mission. A special test science script was used to operate NGIMS in a flightlike manner at two different thermal balance temperatures spanning the NGIMS operational temperature range. Thermal simulations of different phases of the MAVEN orbit were conducted at each balance point. The NGIMS thermal model correlated well with the measured instrument responses and was used to generate on-orbit temperature predicts. The worstcase temperature predicted by these models (Fig. 6) were on the MEB $\mathrm{CDH}$ slice, which reached $34{ }^{\circ} \mathrm{C}$, well below the $+50{ }^{\circ} \mathrm{C}$ design, operating range.

For thermal vacuum testing, the NGIMS instrument flight MLI blanketing was reconfigured to allow for more expeditious temperature transitions for thermal cycling. Eight thermal cycles were performed between the temperature range of $-30{ }^{\circ} \mathrm{C}$ and $+50{ }^{\circ} \mathrm{C}$. Comprehensive performance tests (CPT) were conducted at each temperature plateau and select transitions. In order to compensate for thermal effects in the RF electronics, mass tuning activities were also conducted at various temperatures during the test.

The NGIMS instrument was baked-out at $65^{\circ} \mathrm{C}$ for over 24 hours prior to any thermal tests. Two hot starts were performed at $+50^{\circ} \mathrm{C}$. The cold survival temperature was $-30{ }^{\circ} \mathrm{C}$. The NGIMS temperature was maintained at this level by the NGIMS survival heaters and held in this condition for a $4 \mathrm{~h}$ balance. NGIMS was successfully powered on after this cold survival soak. Two hot and two cold starts were performed with no identifiable issues. 


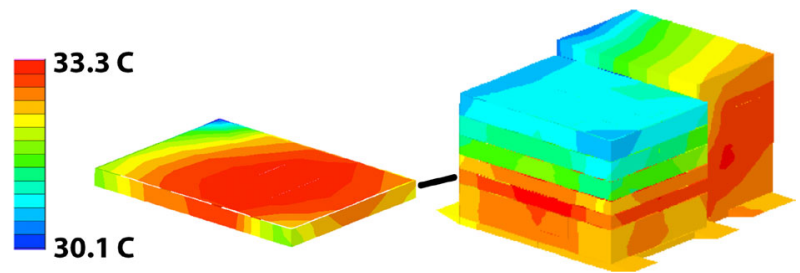

Fig. 6 Thermal analysis for the worst case heating of NGIMS during deep dip; (right) the NGIMS temperatures with MEB slices next to the box containing the mass spectrometer. (Left) the hottest board is the CDH, which is not predicted to reach $34^{\circ} \mathrm{C}$ even in the worst-case deep dip scenario. The design operating range for the NGIMS is $-20^{\circ} \mathrm{C}$ to $+50^{\circ} \mathrm{C}$ and the model for the worst case predicts a good safety margin

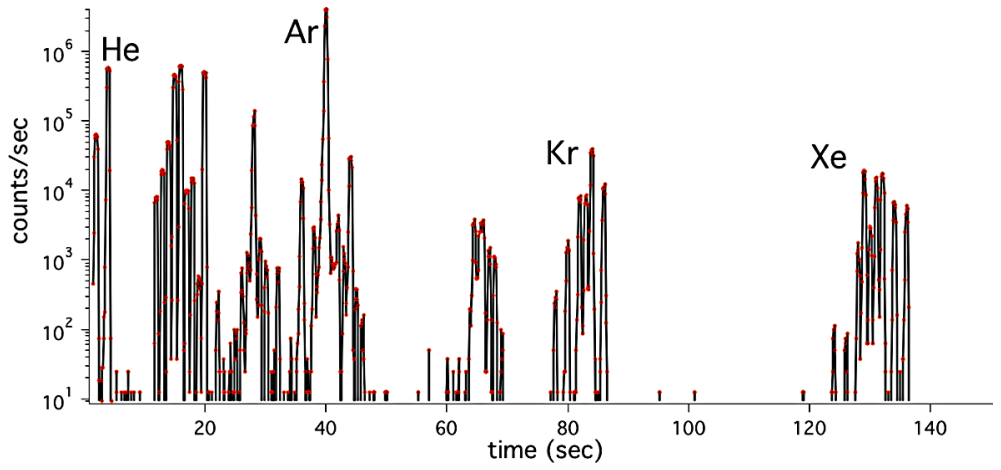

Fig. 7 A fractional scan spectrum taken at 0.1 Da scan step across the full mass range of NGIMS. The mass spectrometer at this point has been baked and processed for flight and pinched off with the noble gases shown sealed in the vacuum of the instrument. A chemical getter pumps active gases. Residual methane is not well pumped by the getter and shows up in the 12-16 Da regions as does background $\mathrm{H}_{2}$ and small amounts of 2 and 3 carbon hydrocarbons released from the hot filament. The signal from these residual gases is expected to be greatly reduced once the break-off cap is removed at Mars. The signal at mass 4 and 5 illustrates that the cross-talk requirements of the instrument of less than $10^{4}$ in an adjacent mass channel are greatly exceeded

The CPT results indicate NGIMS performance was nominal from both an engineering and science acquisition perspective. Mass spectra (Fig. 7) taken of the encapsulated noble gas mix inside the QMS sensor demonstrate stable mass peaks across the entire operational temperature range.

\section{NGIMS Operations and Calibration}

\subsection{Overview of NGIMS Measurement Modes}

NGIMS measurement modes are illustrated in Fig. 8. The prime NGIMS science is realized below $500 \mathrm{~km}$ so above this altitude the instrument will generally be in a low power standby mode with filaments and detectors turned off. Science measurements will typically focus either on neutral gas or ambient ions although the flexible scripting command language will allow these modes to be interleaved if desired. The neutral mode will generally interleave open and closed source measurements (Fig. 9) to allow corrections to be made in the open source measurements for signal variations due to upper atmosphere winds. The 


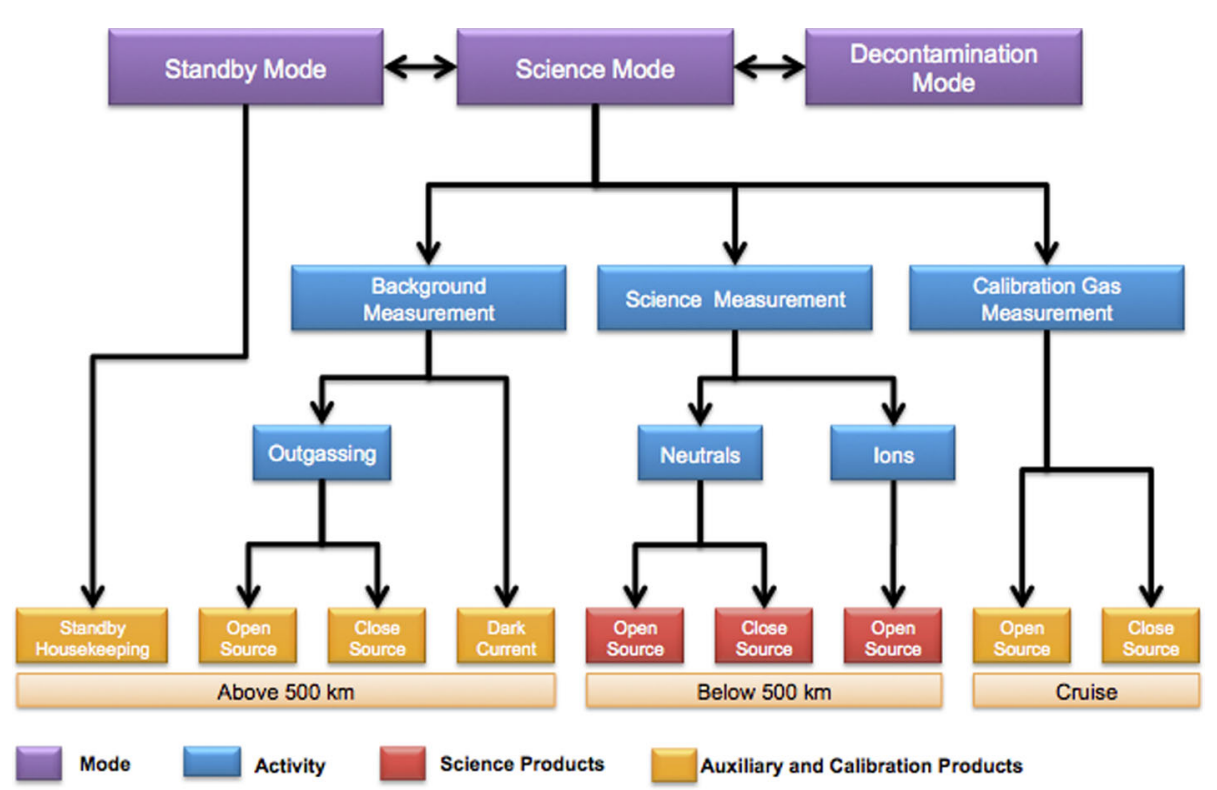

Fig. 8 NGIMS operational modes are illustrated and described in the text
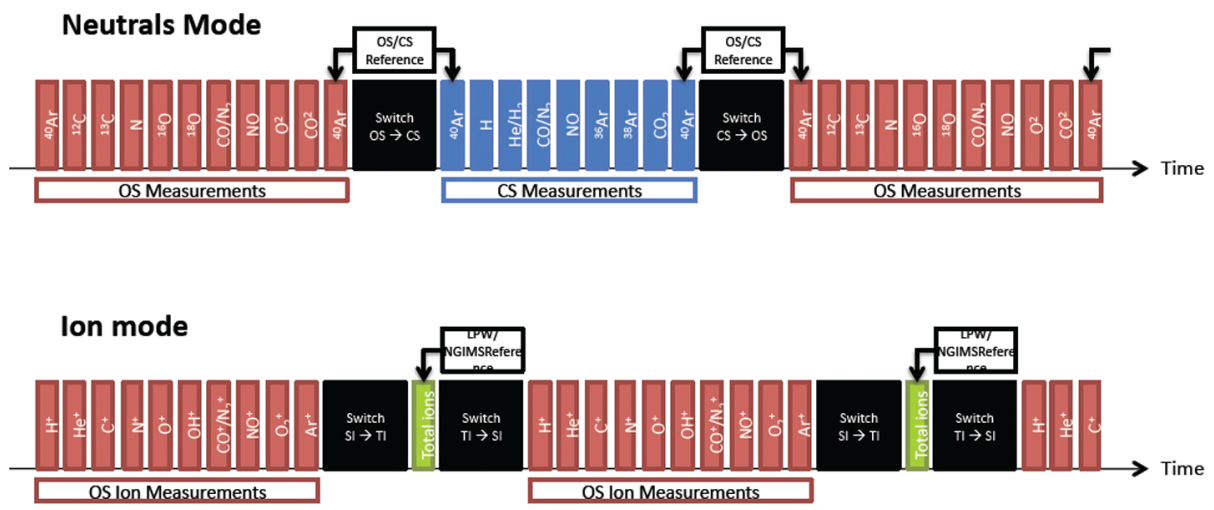

Fig. 9 Example measurement sequences for neutral and ion sequences. In the Neutrals mode the NGIMS will alternate between a set of open and closed source measurements to allow corrections to be made for open source signal attenuation due to neutral winds. Each box along the horizontal time scale represents an integration period of 30 milli-seconds so the entire measurement shown that samples a full set of gases of interest is completed in just over one second

closed source with its $2 \pi$ steradian field of view is quite insensitive to neutral winds. In the ion mode, the total ion signal measured by the NGIMS will be normalized to the LP electron density.

\subsection{Commanding and Operations Overview}

Commanding The primary mode of commanding the instrument is through stored files of commands and code functions called scripts. There are two comprehensive scripts, one func- 
tional and one science, which define all operations desired for the instrument in a modular format. This allows loading smaller configuration scripts to define how the operations will be executed (i.e., which modules to execute). The functional script is stored in EEPROM and configuration files are loaded to define checkout activities, from as simple as an aliveness check to a comprehensive performance test. As would be expected, the science configurations orchestrate the collection scenarios throughout the martian orbits, by interacting much more intensively with the hardware in setting the various DACs, etc.

Individual instrument commands are also used to perform pre-defined functions, such as loading memory or controlling the execution of scripts. These database-defined commands use an upload execution code to define what priority the FSW needs to give to the execution (i.e., store for later or execute immediately).

Science Operations During the science phase of the mission, the NGIMS instrument is scheduled to collect atmospheric measurements according to a pre-established and repeatable operational scenario. According to this scenario, upon reaching an altitude of $\sim 5000 \mathrm{~km}$ along the inbound leg of the orbit, the MAVEN spacecraft will command NGIMS to exit its standby state and start science operations. The instrument FSW will then load the science script from EEPROM along with a configuration file handed by the spacecraft and will proceed into configuring the instrument for operation. During a first phase, the instrument will turn on a pair of filament/multiplier and collect background spectra to provide serve as an assessment of the level of chemical noise in the sensor. At the completion of these background scans, the science script will enter a hold for $\sim 50$ min to allow the instrument to reach its thermal equilibrium. The duration of the warm-up phase is timed to end when the spacecraft descends below $500 \mathrm{~km}$ altitude. Upon reaching the end of the warm-up period, the FSW resume the execution of the science script by setting up the proper voltages for the acquisition mode (neutral ions) and the ion source (open or closed) and acquiring the required mass spectra according to mass tables embedded in the configuration file provided by the spacecraft. The configuration file provides the flexibility of defining customized scanning sequence that can be tailored to specific altitudes and expected signal levels and can alternate between measuring ions and neutrals.

The instrument will continue acquiring measurements for $\sim 25$ min during which the spacecraft would have reached periapsis and accented above $500 \mathrm{~km}$ along its outbound leg before transitioning back to its standby state for the reminder of the orbit. During the mission, the instrument team is expected to generate and uplink to the spacecraft several NGIMS configuration files that are tailored to the atmospheric condition observed at Mars.

Telemetry Telemetry is received by two different methods: real-time dataflow to the Instrument Team Facility (ITF) and post-event file retrieval. In both cases, this data is passed from the Mission Support Area (MSA), through the Science Operation Center (SOC), to the ITF in CCSDS frames. At the ITF, this raw data is unpacked and processed by various dedicated GSE software tools and databases. In addition to science relevant packets, the NGIMS telemetry contains housekeeping data. This data is used for assessment of the health of the instrument. The NGIMS files retrieved from the SOC file system are used to create the comprehensive dataset for the science collection, known as the 'GOLD' dataset. This dataset is then submitted to the repository and fed to a database for use by the MAVEN science team.

\subsection{NGIMS Calibration}

The instrument sensitivity was measured in a static mode for $\mathrm{He}, \mathrm{Ar}, \mathrm{Kr}$, and $\mathrm{Xe}$. In a static mode, the gas is leaked into the ionization source at a very low pressures and left to equilibrate before pressure readings are taken by an external stable ion gage and the corresponding 
Table 3 NGIMS closed source sensitivities for $\mathrm{He}, \mathrm{Ar}$ and $\mathrm{Kr}^{\mathrm{a}}$

\begin{tabular}{lllllll}
\hline Fil \# & $\begin{array}{l}\text { Emission } \\
(\mu \mathrm{A})\end{array}$ & CEM\# & Species & $\begin{array}{l}\text { EI cross } \\
\text { section }^{\mathrm{b}} \\
\left(\mathrm{A}^{\circ}\right)^{2}\end{array}$ & $\begin{array}{l}\text { Absolute } \\
\text { Sensitivity } \\
(\mathrm{cts} / \mathrm{s}) /(\mathrm{part} / \mathrm{cc})\end{array}$ & $\begin{array}{l}\text { Normalized } \\
\text { Sensitivity } \\
(\mathrm{cts} / \mathrm{s}) /(\mathrm{part} / \mathrm{cc}) /\left(\mathrm{A}^{\circ}\right)^{2}\end{array}$ \\
\hline 1 & 250 & 1 & ${ }^{40} \mathrm{Ar}$ & 2.52 & $2.84 \times 10^{-02}$ & $1.13 \times 10^{-02}$ \\
1 & 50 & 1 & ${ }^{40} \mathrm{Ar}$ & 2.52 & $1.83 \times 10^{-03}$ & $7.26 \times 10^{-04}$ \\
1 & 250 & 1 & ${ }^{84} \mathrm{Kr}$ & 3.45 & $2.03 \times 10^{-02}$ & $5.89 \times 10^{-03}$ \\
1 & 50 & 1 & ${ }^{84} \mathrm{Kr}$ & 3.45 & $1.38 \times 10^{-03}$ & $4.00 \times 10^{-04}$ \\
2 & 250 & 2 & ${ }^{40} \mathrm{Ar}$ & 2.52 & $3.03 \times 10^{-02}$ & $1.20 \times 10^{-02}$ \\
2 & 50 & 2 & ${ }^{40} \mathrm{Ar}$ & 2.52 & $2.36 \times 10^{-03}$ & $9.36 \times 10^{-04}$ \\
2 & 250 & 2 & ${ }^{84} \mathrm{Kr}$ & 3.45 & $2.27 \times 10^{-02}$ & $6.57 \times 10^{-03}$ \\
2 & 50 & 2 & ${ }^{84} \mathrm{Kr}$ & 3.45 & $1.90 \times 10^{-03}$ & $5.51 \times 10^{-04}$ \\
\hline
\end{tabular}

${ }^{a}$ This sensitivities will be updated following the first in-flight calibration activity

${ }^{b}$ Electron impact ionization cross sections are from Rejoub et al. (2002)

instrument response is recorded. The measurements from the instrument are processed for dead time correction and background subtraction. After the sensor was pinched off sensitivities were continuously tracked using the noble gas mixture that was sealed in the instrument. During the science phase, small amounts of the flight calibration gas $\left(\mathrm{N}_{2}, \mathrm{CO}_{2}, \mathrm{O}_{2}\right.$, and $\left.\mathrm{Ar}\right)$ will be leaked into the sensor and used to update the sensitivity values that were established during ground calibration for the multiplier voltage and discriminator setting chosen for flight.

Closed Source Sensitivities The sensitivities in the closed source mode for Ar and $\mathrm{Kr}$ are provided in Table 3. Closed source normalized sensitivity $S_{n}$ for another species $s$ of mass $m_{s}$ and electron ionization cross section (at $70 \mathrm{eV}$ ) $\sigma_{s}$ can be approximated to first order through interpolation of the normalized sensitivities of Table 3 according to mass. To derive an absolute sensitivity $S_{a}$ for the species, the normalized sensitivity $S_{n}$ needs to be corrected for RF frequency and for ionization cross-section as:

$$
S_{a}=S_{n} \cdot C_{R F}\left(m_{s}\right) \cdot \sigma_{s}
$$

where $C_{R F}$ is a sensitivity correction factor equal to 0.71 if $\mathrm{ms} \leq 20.5$ and 1.00 if $\mathrm{ms}>20.5$.

Open Source Sensitivities The sensitivity in the open source cannot be derived using the encapsulated calibration gas and will be determined during the science phase by comparing the count rates for non-reactive atmospheric species (for example $\mathrm{He}, \mathrm{N}_{2}$, Ar) that will analyzed during the science phase. This comparison will be accomplished by switching alternately between the open and the closed source. The absolute sensitivity of the open source $O_{a}$ is given by

$$
O_{a}=\frac{S_{a}\left(m_{r e f}\right) \cdot n_{c}\left(m_{r e f}\right)}{n_{o}\left(m_{r e f}\right)} \cdot C_{E N}\left(m_{s}\right)
$$

where $n_{c}$ is the dead time corrected count rate of a reference species $m_{\text {ref }}$ as measured by the closed source, $n_{o}$ is the dead time corrected count rate of the same reference species as measured by the open source. $C_{E N}$ is the energy correction factor to be applied to account for the energy response of the open source. This correction factor will be derived in the early days of the science phase. 
Ion Sensitivities Ions are sampled through the open source with the filaments on this source turned off and the ion deflector plates that sweep ions away during open source neutral measurements set to enable ions to enter the quadrupole deflector. The deflectors will be scanned early in the mission to validate the deflector voltages selected from simulations and will be adjusted as necessary. Precise sensitivity for ions can be derived using concurrent LPW electron density measurements. The absolute sensitivity for a given ion species is given by

$$
I_{a}=\frac{D_{e}}{n_{I}} \cdot C_{E N}\left(m_{s}\right)
$$

where $n_{I}$ is the sum of all dead time corrected count rate for all mass channels. $D_{e}$ is the time interpolated LPW electron density measurements. $C_{E N}$ is the energy correction factor to be applied to account for the energy response of the instrument. This correction factor is identical to the one derived for the open source.

Calibration Configuration The calibration of the mass spectrometer prior to pinch of and qualification tests was carried out with the ion source cover replaced with a flanged transition joint that coupled the sensor to a static calibration chamber. Gas mixtures were introduced into the NGIMS in a mixing manifold and the response of the instrument established over a range of pressures. Variations in the instrument response over the course of the environmental tests were enabled by leaving a mixture of noble gases that the NGIMS getter does not pump ( $\mathrm{He}, \mathrm{Ar}, \mathrm{Kr}, \mathrm{Xe}$ ) in the instrument to provide a signal over wide mass range.

Figure 7 shows a 0.1 amu resolution spectrum of this noble gas mixture collected in the closed source mode with a filament emission set to $50 \mu \mathrm{A}$. The spectrum shows the noble gases mass peaks along with chemical background due to filament and sensor wall outgassing $\left(\mathrm{CH}_{4}, \mathrm{H}_{2} \mathrm{O}, \mathrm{CO}, \mathrm{CO}_{2}\right.$, etc. $)$. This background level is typical of a sealed sensor and will be orders of magnitude lower once the break-off is ejected and the ion source is exposed to the vacuum of space.

Instrument Sensitivity Reference instrument sensitivities were derived using static gas measurements of noble gases in the closed source under both high and low emission settings. In high emission setting the instrument sensitivity for static gas was measured to be respectively $2 \times 10^{-3}$ counts/s/part/cc for ${ }^{4} \mathrm{He}, 2.8 \times 10^{-2}$ counts/s/part/cc for ${ }^{40} \mathrm{Ar}$, and $2.0 \times 10^{-2}$ counts/s/part/cc for ${ }^{84} \mathrm{Kr}$. Since instrument sensitivity is a function of molecular cross section, further calibration on an analogous laboratory unit are being conducted to permit the extrapolation of these noble gas sensitivities to active gases of relevance to the Martian upper atmosphere. Instrument sensitivities measured in static mode have to be corrected by the ram enhancement factor provided by Eq. (1) expressed for each measured species.

Cross Talk and Linearity Using ${ }^{4} \mathrm{He}$ peaks the adjacent mass cross-talk was measured to be less than $6 \times 10^{-5}$. The cross talk performance means that this will not be a limiting factor in securing isotope ratios of interest in the atmosphere.

During the calibration phase, the linearity of the channel electron multipliers was measured up to the detector saturation. Figure 10 shows that detectors operate in a linear regime up to $5 \times 10^{6}$ counts per second above which careful dead time correction is needed. To avoid operating in a deadtime correction region, the sensor ion optics will be commanded to a "de-tuned" setting by the FSW at preset altitudes. In this de-tuned setting, the ion beam that is existing the ion source is defocused which allows to electronically reduce the instrument sensitivities for species with signal levels that are reaching the limit of the detector dynamic range. 
Fig. 10 Detector linearity measured for the closed source at high and low filament emissions using $\mathrm{Ar}$ (top) and $\mathrm{Kr}$ (bottom). These curves show that the channel electron multipliers exhibit good linearity up to $\sim 10^{6}$ counts/s. Above that limit, a careful correction for dead time is required

Fig. 11 Spectra of $\mathrm{Ar}$ and $\mathrm{CO}_{2}$ gases collected for different instrument temperatures demonstrate the stability of the $\mathrm{RF}$ circuit over a wide range of temperatures. TID designates the test ID
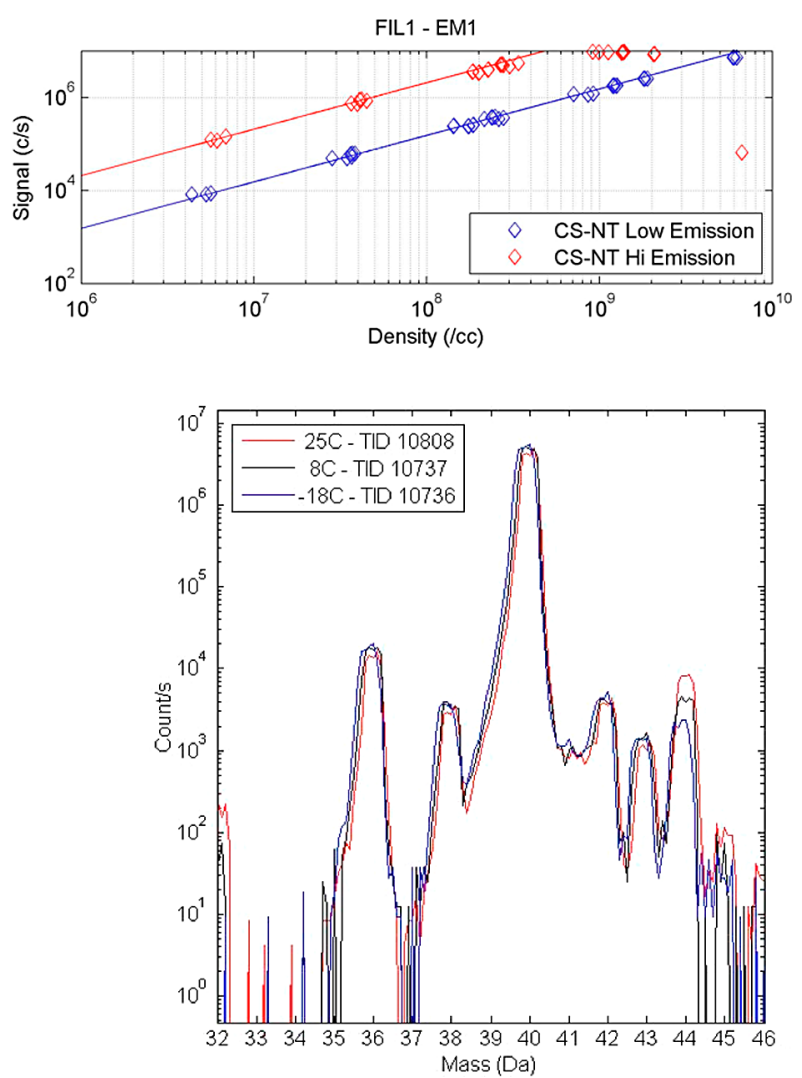

Temperature Stability Finally the comparison of spectra collected at different instrument operational temperatures (Fig. 11) showed that mass peaks location is maintained to better than 0.2 amu which confirms the stability of the instrument RF circuit.

In Situ Calibration and Characterization Further characterization during the cruise and commissioning phases will provide the required refinement of the calibration and will allow the complete characterization of the instrument in its operational environment. The in situ calibration runs will be carried out over the course of the mission to search for any long term changes in instrument performance.

\subsection{Summary}

The extended MAVEN mission duration is expected to greatly extend the single point entry measurements made by the mass spectrometers on the Viking aeroshells. The NGIMS will provide complementary measurements to the two other MAVEN measurement suites in the study of atmospheric processes that are important for understanding atmospheric loss.

Acknowledgements The NGIMS development was funded by the Science Mission Directorate of the National Aeronautics and Space Administration.

Open Access This article is distributed under the terms of the Creative Commons Attribution License which permits any use, distribution, and reproduction in any medium, provided the original author(s) and the source are credited. 


\section{References}

S.K. Atreya, M.G. Trainer, H.B. Franz, M.H. Wong, H.L.K. Manning, C.A. Malespin, P.R. Mahaffy, P.G. Conrad, L.A. Leshin, J.H. Jones, C.R. Webster, T.C. Owen, R.O. Pepin, R.N. Gonzalez, The primordial argon isotope fractionation in the atmosphere of Mars measured by the MSL/SAM instrument, and implications for atmospheric loss. J. Geophys. Res. TBD (2013)

R.H. Becker, R.O. Pepin, The case for a Martian origin of the shergottites-nitrogen and noble gases in EETA 79001. Earth Planet. Sci. Lett. 69, 225 (1984)

J.-L. Bertaux, O. Korablev, D. Fonteyn, S. Perrier, A. Fedorova, F. Montmessin, F. Leblanc, S. Lebonnois et al., in Mars Express: The Scientific Investigations, vol. 1291, ed. by K.W. Fletcher O (ESA, Noordwijk, 2009), pp. 139-197. Special publication

D.D. Bogard, D.H. Garrison, Relative abundances of argon, krypton, and xenon in the Martian atmosphere as measured in Martian meteorites. Geochim. Cosmochim. Acta 62, 1829 (1998)

D.D. Bogard, P. Johnson, Martian gases in an Antarctic meteorite. Science 221, 651 (1983)

S.W. Bougher, S. Engel, D.P. Hinson, J.R. Murphy, MGS radio science electron density profiles: interannual variability and implications for the martian neutral atmosphere. J. Geophys. Res., Planets 109, 3010 (2004)

A.F. Chicarro, O.G. Witasse, A. Pio Rossi, in Mars Express: The Scientific Investigations, vol. 1291, ed. by K.W. Fletcher O (ESA, Noordwijk, 2009), pp. 3-11. Special publication

B.L. Ehlmann et al., Orbital identification of carbonate-bearing rocks on Mars. Science 322, 1828 (2008)

J.L. Fox, On the escape of oxygen and hydrogen from Mars. Geophys. Res. Lett. 20, 1747 (1993a)

J.L. Fox, The production and escape of nitrogen atoms on Mars. J. Geophys. Res. 98, 3297 (1993b)

W.B. Hanson, S. Sanatani, D.R. Zuccaro, The martian ionosphere as observed by the Viking retarding potential analyzers. J. Geophys. Res. 82, 4351 (1977)

B. Jakosky, The 2013 Mars Atmosphere and Volatile Evolution (MAVEN) mission to Mars. Space Sci. Rev. (2014. submitted)

B.M. Jakosky, R.O. Pepin, R.E. Johnson, J.L. Fox, Mars atmospheric loss and isotopic fractionation by solarwind-induced sputtering and photochemical escape. Icarus 111, 271 (1994)

W. Kasprzak et al., Paper presented at the Society of Photo-Optical Instrumentation Engineers (SPIE) Conference Series October 1, 1996.

R. Lundin et al., ASPERA/Phobos measurements of the ion outflow from the martian ionosphere. Geophys. Res. Lett. 17, 873 (1990)

R. Lundin, S. Barabash, M. Holmström, H. Andersson, M. Yamauchi, H. Nilsson et al., in Mars Express: The Scientific Investigations, vol. 1291, ed. by K.W. Fletcher O (ESA, Noordwijk, 2009), pp. 199-215. Special publication

P.R. Mahaffy, Characteristics of an electrostatic quadrupole deflector. J. Vac. Sci. and Technol. 8, 3244-3246 (1990)

P.R. Mahaffy et al., The sample analysis at Mars investigation and instrument suite. Space Sci. Rev. 170, 401 (2012)

P.R. Mahaffy, C.R. Webster, S.K. Atreya, H. Franz, M. Wong, P.G. Conrad, D. Harpold, J.J. Jones, L.A. Leshin, H. Manning, T. Owen, R.O. Pepin, S. Squyres, M. Trainer, Abundance and Isotopic composition of gases in the martian atmosphere from the Curiosity Rover. Science 341, 263-266 (2013)

P.R. Mahaffy et al., The neutral mass spectrometer on the lunar atmosphere and dust environment explorer mission. Space Sci. Rev. (2014). doi:10.1007/s11214-014-0043-9

J.P. McFadden, O. Kortmann, D. Curtis, G. Dalton, G. Johnson, R. Abiad, R. Sterling, K. Hatch, P. Berg, C. Tiu, D. Gordon, S. Heavner, M. Robinson, M. Marckwordt, R. Lin, B. Jakosky, MAVEN SupraThermal And Thermal Ion Compostion (STATIC) instrument. Space Sci. Rev. (2014, this issue)

H.J. Melosh, A.M. Vickery, Impact erosion of the primordial atmosphere of Mars. Nature 338, 487 (1989)

H.B. Niemann et al., Pioneer Venus orbiter neutral gas mass spectrometer experiment. IEEE Trans. Geosci. Remote Sens. 18, 60 (1980)

H.B. Niemann et al., Galileo Probe Mass Spectrometer experiment. Space Sci. Rev. 60, 111 (1992)

H.B. Niemann et al., The Planet-B neutral gas mass spectrometer. Earth Planets Space 50, 785 (1998)

H.B. Niemann et al., The gas chromatograph mass spectrometer for the Huygens probe. Space Sci. Rev. 104, 553 (2002)

A.O. Nier, M.B. Mcelroy, Structure of neutral upper-atmosphere of Mars-results from Viking 1 and Viking 2. Science 194, 1298 (1976)

A.O. Nier, M.B. Mcelroy, Composition and structure of Mars upper-atmosphere-results from neutral mass spectrometers on Vikings 1 and 2. Eos 58, 827 (1977)

T. Owen et al., The composition of the atmosphere at the surface of Mars. J. Geophys. Res. 82, 4635 (1977) 
M. Pätzold, S. Tellmann, T. Andert, L. Carone, M. Fels, R. Schaa, C. Stanzel, I. Audenrieth-Kersten, A. Gahr, A.L.S. Müller B, D. Stupar, C. Walter, B. Häusler, S. Remus, J. Selle, H. Griebel, W. Eidel, S. Asmar, G.K. Goltz D, J.P. Barrio, V. Dehant, M. Beuthe, P. Rosenblatt, O. Karatekin, V. Lainey, G.L. Tyler, D.S. Hinson R, J. Twicken, in Mars Express: The Scientific Investigations, vol. 1291, ed. by K.W. Fletcher O (ESA, Noordwijk, 2009), pp. 217-245. Special publication

R.O. Pepin, Meteorites: evidence of Martian origins. Nature 317, 473 (1985)

R.O. Pepin, On the origin and early evolution of terrestrial planet atmospheres and meteoritic volatiles. Icarus 92, 2 (1991)

R.O. Pepin, Evolution of the martian atmosphere. Icarus 111, 289 (1994)

J.J. Plaut, G. Picardi, T.W. Watters, D.A. Gurnett (MARSIS Science Team), in Mars Express: the Scientific Investigations, vol. 1291, ed. by K.W. Fletcher O (ESA, Noordwijk, 2009), pp. 97-114. Special publication

R. Rejoub, B.G. Lindsay, R.F. Stebbings, Determination of the absolute partial and total cross sections for electron-impact ionization of the rare gases. Phys. Rev. A 65, 42713 (2002)

N.W. Spencer, G.R. Carignan, In situ measurements of thermospheric composition, temperature, and winds by mass spectrometry. Adv. Space Res. 8, 107 (1988)

T.D. Swindle, M.W. Caffee, C.M. Hohenberg, Xenon and other noble gases in shergottites. Geochim. Cosmochim. Acta 50, 1001 (1986)

M.I. Verigin et al., Ions of planetary origin in the martian magnetosphere (Phobos 2/TAUS experiment). Planet. Space Sci. 39, 131 (1991)

J. Veverka et al., Comet nucleus tour. Acta Astronaut. 35, 181 (1995)

J.H. Waite et al., The Cassini ion and neutral mass spectrometer (INMS) investigation. Space Sci. Rev. 114, 113 (2004)

C.R. Webster, P.R. Mahaffy, G.J. Flesch, P.B. Niles, J.H. Jones, L.A. Leshin, S.K. Atreya, J. Stern, L.C. Christensen, T. Owen, H. Franz, R.O. Pepin, A. Steele (MSL Science Team), Isotope ratios of H, C, and $\mathrm{O}$ in $\mathrm{CO}_{2}$ and $\mathrm{H}_{2} \mathrm{O}$ of the martian atmosphere. Science 341, 260-263 (2013a)

C.R. Webster, P.R. Mahaffy, L.A. Leshin, S.K. Atreya, G.J. Flesch, J. Stern, L.C. Christensen, A.R. Vasavada, T. Owen, P.B. Niles, J.H. Jones, Mars atmospheric escape recorded by H, C and O isotope ratios in carbon dioxide and water measured by the SAM tunable laser spectrometer on the Curiosity Rover, in $\operatorname{LPSC}$ XLIV (2013b)

R.C. Wiens, R.O. Pepin, Laboratory shock emplacement of noble gases, nitrogen, and carbon dioxide into basalt, and implications for trapped gases in shergottite EETA 79001. Geochim. Cosmochim. Acta 52, 295 (1988)

P. Withers, Mars Global Surveyor and Mars Odyssey Accelerometer observations of the martian upper atmosphere during aerobraking. Geophys. Res. Lett. 33, 2201 (2006)

P.B. Wurz, A. Balogh, V. Coffey, B.K. Dichter, W.T. Kasprzak, A.J. Lazarus, W. Lennartsson, J.P. McFadden, in ISSI Scientific Report, ed. by M. Wüest, D.S. Evans, R. von Steiger (International Space Science Institute, Bern, 2007) 